\title{
Smoking history and the efficacy of immune checkpoint inhibitors in patients with advanced non-small cell lung cancer: a systematic review and meta-analysis
}

\author{
Da-Li Chen, Qing-Yuan Li, Qun-You Tan \\ Department of Thoracic Surgery, Daping Hospital, Army Medical University, Chongqing, China \\ Contributions: (I) Conception and design: DL Chen, QY Tan; (II) Administrative support: QY Tan; (III) Provision of study materials or patients: QY \\ Tan; (IV) Collection and assembly of data: DL Chen, QY Tan; (V) Data analysis and interpretation: DL Chen, QY Li; (VI) Manuscript writing: All \\ authors; (VII) Final approval of manuscript: All authors. \\ Correspondence to: Qun-You Tan, MD, PhD. Department of Thoracic Surgery, Daping Hospital, Army Medical University, \#10 Changjiangzhilu \\ Daping, Yuzhong District, Chongqing 400042, China. Email: tanqy001@163.com.
}

Background: Some studies imply a strong correlation between smoking history and the efficacy of immune checkpoint inhibitors (ICIs) in patients with advanced non-small cell lung cancer (NSCLC). Hence, a systematic review and meta-analysis was conducted to comprehensively investigate this correlation.

Methods: Three online databases including PubMed, Embase and Cochrane Library were searched. Abstracts and presentations from European Society of Medical Oncology (ESMO) and American Society of Clinical Oncology (ASCO) were also reviewed. The deadline of search was Nov 9, 2019. Randomized clinical trials (RCT) of ICIs that reported hazard ratio (HR) for overall survival (OS) or progressive-free survival (PFS) by the smoking status of NSCLC patients were eligible for our study. We focused on publications issued in English. A random effects model was implemented in the synthesis, and a two-step interaction test was used to investigate the difference of ICIs efficacy among patients with different smoking histories.

Results: Twelve RCTs involving 6,497 NACLC patients [5,569 (85.72\%) current/former smokers and 928 (114.28\%) never smokers] were eligible for our systematic review and meta-analysis. The pooled HRs [95\% confidential interval (CI)] of OS and PFS were $0.74(0.67,0.81)$ and $0.72(0.59,0.88)$ respectively for current/former smokers in the experimental group with ICIs versus those in the control group. The pooled HRs $(95 \%$ CI) of OS and PFS were $0.81(0.60,1.08)$ and $0.92(0.55,1.54)$ respectively for never smokers in the experimental group with ICIs compared with those in the control group. The difference of ICIs efficacy in terms of OS between current/former and never smokers was insignificant [interaction HR (95\% CI), 0.77 $(0.69,0.86), \mathrm{I}^{2}=25.4 \%$, P_hetero=0.21].

Conclusions: The efficacy of ICIs in patients with smoking history is seemingly superior over patients without smoking history, but insignificantly. The difference can be explained by several factors such as insufficient sample size of non-smokers, and confounding factors. We suggest that smoking history cannot be recognized as a predictor of immune therapy in advanced NSCLC.

Keywords: Immune checkpoint inhibitors (ICIs); non-small cell lung cancer (NSCLC); smoking history; metaanalysis

Submitted May 16, 2020. Accepted for publication Sep 01, 2020.

doi: $10.21037 /$ jtd-20-1953

View this article at: http://dx.doi.org/10.21037/jtd-20-1953

(C) Journal of Thoracic Disease. All rights reserved. 


\section{Introduction}

Lung cancer is one of the most fatal human cancers worldwide $(1,2)$, and non-small cell lung cancer (NSCLC) accounts for more than $80 \%$ of its total subtypes. The majority of NSCLC patients are diagnosed at the advanced stage without opportunity of radical surgery. Cisplatinbased two-drug therapy is the standard chemotherapy. The members of immune checkpoint inhibitors (ICIs) mainly involving three types of monoclonal antibody [antiprogrammed cell death 1 (PD-1), PD ligand 1 (PD-L1) and anti-cytotoxic T lymphocyte associated antigen 4 (CTLA-4) inhibitors] are introduced into the treatment of advanced cancers, including advanced or metastatic NSCLC (3-5). Recently, dozens of randomized clinical trials (RCTs) demonstrate that addition of ICIs into conventional chemotherapy can significantly improve the survival outcomes of advanced NSCLC patients compared with placebo plus conventional chemotherapy $(4,6-13)$.

Nevertheless, only specific subgroups of patients substantially benefit from the addition of ICIs into the systemic treatment. Thus, it is necessary to identify some key indicators to guide clinical practice and maximize the efficacy of ICIs. The existing research indicates that the expression status of PD-L1 is an independent predictor of the efficacy of ICIs in advanced NSCLC (14-16). Recently, a high-rank meta-analysis analyzing twenty RCTs concludes that even though ICIs can improve the overall survival (OS) of advanced cancer patients, the magnitude of benefit is sexdependent (17). Male patients benefit significantly more from the addition of ICIs than female patients do. Hence, patient gender can be a clinical predictor of ICI efficacy. In terms of other clinicopathologic features, subgroup analysis of related RCTs suggests that smoking history can be a predictor of ICI efficacy in advanced NSCLC patients.

Subgroup analysis by clinical characteristics in the CheckMate 078 study (18) demonstrates that patients with smoking history treated with ICIs in the experimental group have a significant longer OS than those in the control group. Even though patients without smoking history in the experimental group show a prolonged OS compared with the control group, the difference is insignificant. In addition, an updated subgroup analysis of KEYNOTE-024 study discovers that the difference of ICI efficacy is only significant in subgroup of ever smokers [hazard ratio (HR) $=0.59(0.41-0.85)](19)$. However, several shortcomings in these RCTs may weaken the reliability of their evidences. For example, most studies only recruit a small group of non- smokers, which results in a wide confidential interval (CI) for relative HR. In addition, smoking history significantly correlates with tumor mutational burden (TMB) status in patients with advanced NSCLC $(20,21)$. Thus, factors such as TMB may also play a role in evaluating the predictive value of smoking status.

Therefore, it is necessary to conduct a systematic review and meta-analysis to summarize the current evidences and assess whether or not different smoking histories can predict the efficacy of ICIs in advanced NSCLC patients. We present this systematic review and meta-analysis in accordance with the PRISMA reporting checklist (available at http://dx.doi.org/10.21037/jtd-20-1953).

\section{Methods}

There is no review protocol for the study.

\section{Inclusion and exclusion criteria}

A study conforming with the following criteria was regarded as up to standard: (I) being conducted according to the design of RCT; (II) focusing on the efficacy of ICIs (PD-1/PD-L1/CTLA-4 inhibitors) in advanced NSCLC; (III) reporting survival outcomes including either OS or progressive-free survival (PFS) and the related HR (95\% CI); (IV) performing a subgroup analysis of HR (95\% CI) by smoking history. The exclusion criteria were: (I) nonRCT, cohort study, case-control study or case series; (II) other study types including case report, reviews and metaanalysis; (III) investigating the efficacy of ICIs in other types of cancers or not focusing on advanced NSCLC; (IV) published protocol of RCT; (V) lack of subgroup analysis by smoking history; (VI) publication in a non-English journal; (VII) involvement of ICIs-treated participants in the control group.

\section{Search strategies}

The target online databases were PubMed, Embase and Cochrane Library. Because most of English references were cited in PubMed and Embase, it guaranteed the comprehensiveness of information retrieval. The search of Cochrane Library can help to identify whether or not our study is duplicated. In addition, we manually retrieved abstracts and presentations from European Society of Medical Oncology (ESMO) and American 
Society of Clinical Oncology (ASCO) in case of omission. The deadline of search was Nov. 9, 2019. The search strategies were formulated based on the following keywords: "non-small cell lung cancer", "NSCLC", "immune checkpoint inhibitors", "anti-programmed cell death 1", "anti-programmed cell death ligand 1", "anti-cytotoxic T lymphocyte associated antigen 4", “avelumab”, “durvalumab”, “atezolizumab”, “ipilimumab”, "pembrolizumab", "nivolumab" and "random*". The repeatable search strategies for the three databases were displayed in Appendix 1. Furthermore, the reference lists of the included papers were screened for eligible studies.

\section{Study screening and data retrieval}

EndNote X7 was used to screen potential references. After searching online databases, the entire reference lists were downloaded and imported in the software. First, the duplicate references were deleted by automatic and manual classification. Then, the references focusing on other cancer types than NSCLC were removed. Third, papers designed as non-RCT, cohort study, case-control study, case series, case report, review or meta-analysis were excluded. Next, studies involving ICIs-treated participants in the control group were regarded as disqualification. After the above steps, the full texts of the remaining studies were reviewed. If several publications originated from the same project, the one with comprehensive and up-to-date data was our target.

From each eligible study, we extracted the title (if the title was unobtainable, the name of first author + publication year was used instead), registration number of study protocol, histological subtype, median age of participants (years), randomization ratio, regimes in experimental and control groups, line of therapy, number of patients (including never and current/former smokers), duration of follow-up (month, minimum or median data), study drugs, and HRs (95\% CI) of OS and PFS by different smoking histories. In addition, information of methodology in terms of random sequence generation, allocation concealment, blinding method, incomplete outcome data and selective reporting was also extracted to assess the risk of bias according to Cochrane Handbook for Systematic Review of Interventions (22). We carefully compared the methods and results of published articles with the corresponding registered protocol. The detailed table of "risk of bias" was reported in Table S1. The "risk of bias" figure was displayed together with a forest plot.

\section{Data analysis}

All steps of analysis were performed in Review Manager 5.3. The primary outcome in the systematic review and metaanalysis is the difference of ICI efficacy between current/ former and never smokers. Other outcomes included the difference of the PFS $\log$ (HR) between current/former and never smokers, and the pooled OS and PFS HRs ( $95 \% \mathrm{CI}$ ) for current/former or never smokers treated in the experimental group versus those treated in the control group. The pooled HRs were calculated using random effect models. The statistical significance was defined as $\mathrm{P}<0.05$ and 1 did not fill into the $95 \%$ CI. Some trials reported the HRs (95\% CI) of current and former smokers separately, we calculated the HR of current/former smokers by pooling the two HRs (95\% CI). We did a two-step interaction analysis [recommended by Fisher et al. (23)] to identify who (never or current/former smokers) benefits more from ICI treatment. First, we calculated an interaction trial specific HR (95\% CI) from the reported HR $(95 \%$ $\mathrm{CI})$ of never and current/former smokers in each trial. Second, these trial-specific interaction HRs (95\% CI) were combined according to a random effect model. A P value (named as 'P_hetero') was given to judge the heterogeneity between the two estimates. $\mathrm{P} \_$hetero $<0.05$ suggested a significant difference of ICI efficacy between current/ former and never smokers. In addition, subgroup analysis was conducted according to therapy line $\left(1^{\text {st }}\right.$ line and $>1^{\text {st }}$ line), study drug (PD-1 inhibitors and CTLA-4 inhibitors) and histological types of NSCLC (nonsquamous, squamous, and unclassified). The heterogeneity across these trials was assessed by the $\mathrm{I}^{2}$ statistics and related $\mathrm{P}$ value. $\mathrm{I}^{2}>50 \%$ or $\mathrm{P}<0.05$ indicated severe heterogeneity. Therefore, subgroup analysis should be conducted and the explanation of related pooled HR (95\% CI) should take a cautious stand. Publication bias was estimated using funnel plots.

\section{Results}

Records identified through online database search and other sources were 4,529 and 12, respectively. After deleting duplication, 2,917 studies were screened out by titles and abstracts and then 2,020 publications were reviewed by screening full texts. Finally, 12 RCTs $(18,19,24-33)$ fulfilled the inclusion and exclusion criteria (Figure 1). All studies were published from 2015 to 2019, except for one study published in 2009. Among them, 10 RCTs focused on 


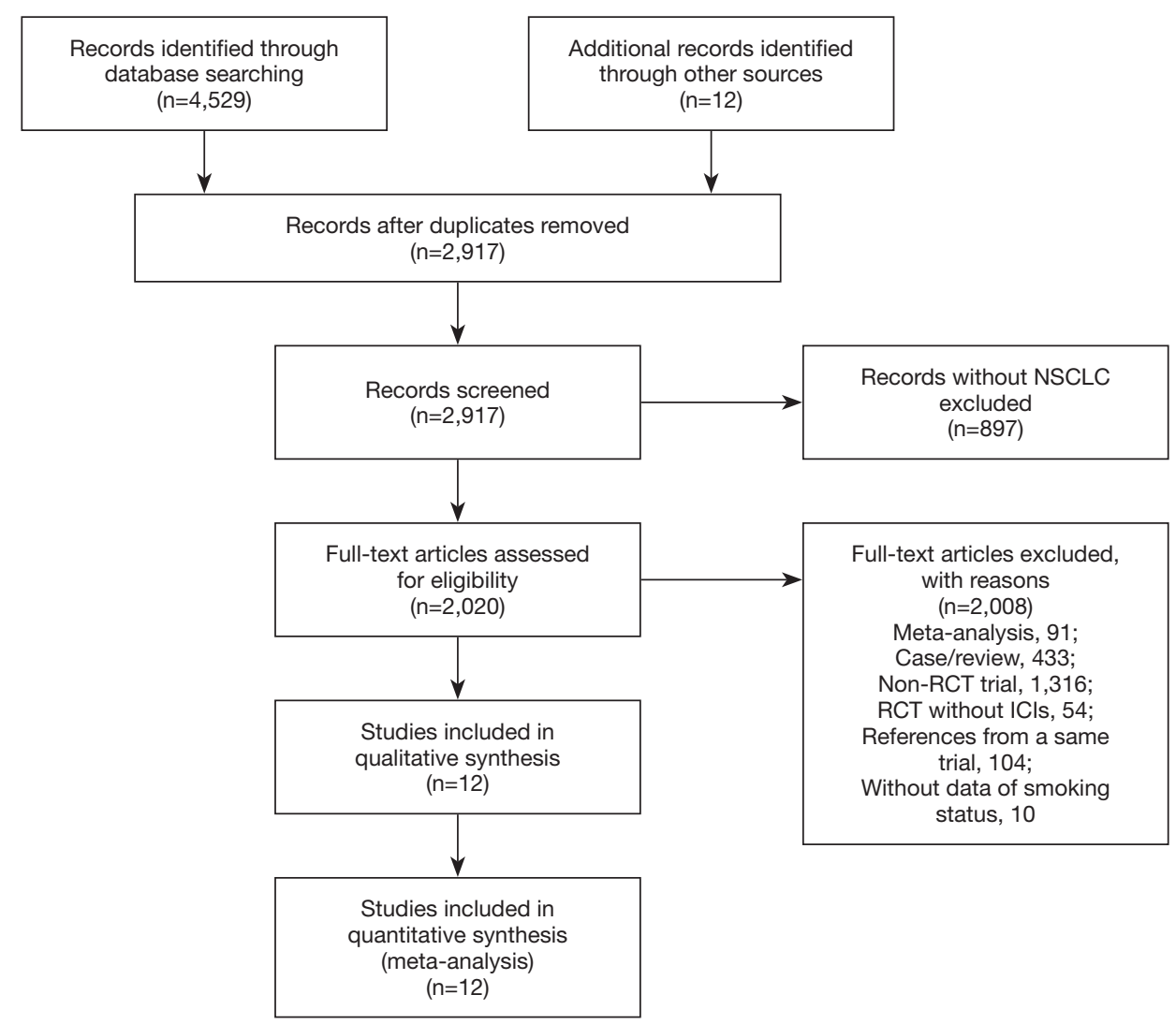

Figure 1 The PRISMA search steps of our systematic review and meta-analysis. Twelve randomized clinical trials reporting smoking status specific hazard ratio were finally eligible for our pooled analysis.

PD-1 inhibitors (two on atezolizumab, one on avelumab, one on durvalumab, two on pembrolizumab, and four on nivolumab), one RCT focused on CTLA-4 inhibitor (ipilimumab) and one study focused on PD-1 and CTLA-4 inhibitors (ipilimumab and nivolumab) (Table 1).

All the included RCTs were designed as phase III study and the registration numbers were reported in all but one published paper. They all focused on the advanced stage (IIIB/IV or unresectable) or metastatic or recurrent NSCLC. Specifically, four RCTs focused on the histological subtype of nonsquamous carcinoma and two RCTs focused on the histological subtype of squamous carcinoma. Five RCTs investigated the efficacy of ICIs added to standard chemotherapy as $1^{\text {st }}$ line therapy compared with standard chemotherapy. Six RCTs focused on the role of ICIs as $>1^{\text {st }}$ line treatment versus docetaxel $\left(75 \mathrm{mg} / \mathrm{m}^{2}\right)$. And one study evaluated the efficacy of pembrolizumab $(200 \mathrm{mg})$ added to pemetrexed and a platinum-based drug followed by pembrolizumab as $>1^{\text {st }}$ line therapy compared with placebo added to pemetrexed and a platinum-based drug followed by placebo (Table 1).

The sample size across the included studies ranged from 272 to 1,225 (median 555), the number of never smokers ranged from 22 to 335 (median 78), and the median age of participants across varied from 56 to 65 years. Of the total 6,497 NACLC patients included, 5,569 (85.72\%) were current/former smokers and 982 (14.28\%) were never smokers. Except for two studies not reporting the median/ minimum follow-up length, four studies reported the length of minimum follow-up ranging from 11.2 to 13.7 months and eight studies presented the length of median follow-up ranging from 10.5 to 33.3 months.

Totally $3,404(61.12 \%)$ patients across ten of the included studies were reported with PD-L1 expression of at least $1 \%$. Two RCTs did not report the information of PD-L1 expression. Only five trials displayed the situation of EGFR (total of 346 patients) or KRAS mutation (totally 152 patients). In addition, all participants included in the CheckMate 227 trial (30) were under high level of TMB. Other included studies did not refer to TMB. 
Table 1 The baseline characteristics of the included studies in our systematic review and meta-analysis

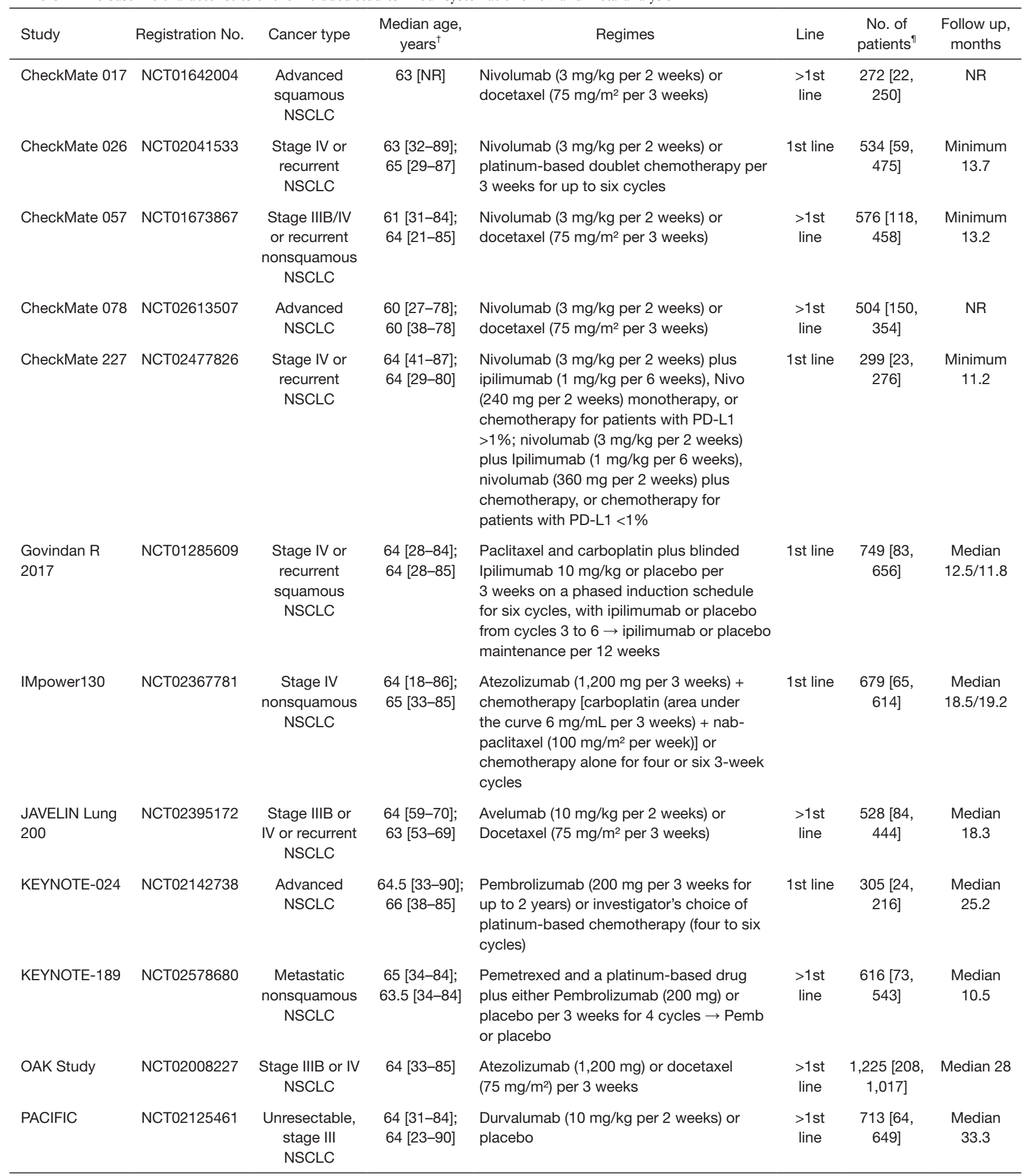

\footnotetext{
${ }^{\dagger}$, the order is that the age of experimental group followed by the age of control group; ${ }^{n}$, the order in the bracket is that the number of never
} smokers followed by the number of current/former smokers. NR, not refer; NSCLC, non-small cell lung cancer. 


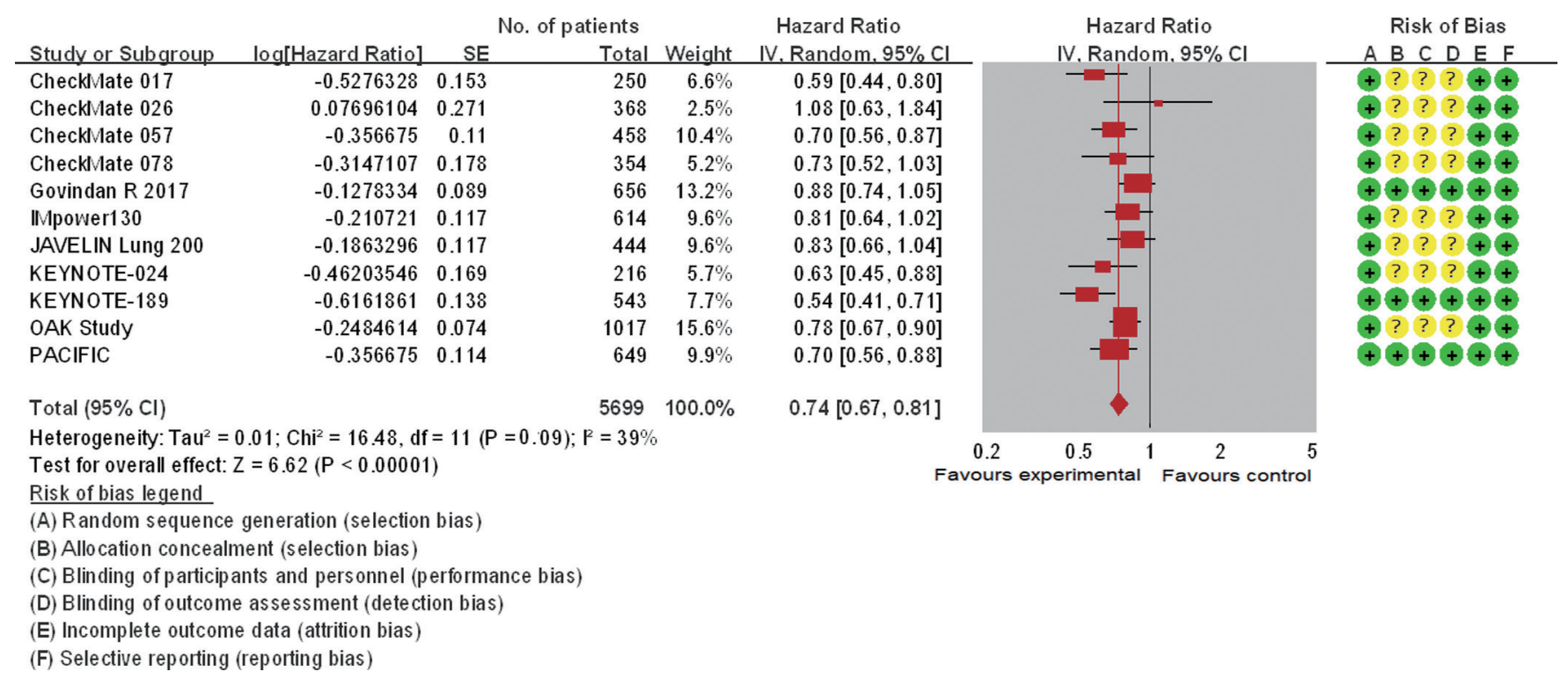

Figure 2 The forest plot displayed overall survival (OS) of current/former smokers. The risk of bias mainly originated from allocation concealment, blinding of participants and personnel, and blinding of outcome assessment. And only mild heterogeneity existed across these studies. The pooled hazard ratio based on a random effect model showed a significant improvement of OS in the experimental group versus control group $(\mathrm{P}<0.00001)$.

The risk of bias of each included trial was analyzed according to the Cochrane standard. The randomized allocation sequences were generated in every trial with different ratios (1:1, 2:1 or 1:1:1). Three RCTs were doubleblinded. The majority of trials were in danger of selection, performance, and detection biases. All studies reported the results in accordance with the corresponding study protocol and showed low risk of attrition and reporting biases. The details of risk of bias were displayed in Table S1.

Eleven trials involving 5,569 patients and seven trials involving 2,970 participants analyzed the efficacy of ICIs (OS and PFS, respectively) in current/former smokers in the experimental group compared with those in the control group. Patients with smoking history in the experimental group showed a significantly reduced risk of death [pooled $\mathrm{HR}=0.74$ (0.67, 0.81), $\mathrm{P}<0.00001, \mathrm{I}^{2}=39 \%$, Figure 2] or disease progression [pooled HR $=0.72(0.59,0.88)$, $\mathrm{P}<0.0001, \mathrm{I}^{2}=80 \%$, Figure 3] compared with those in the control group. Similar but smaller benefits were observed in patients without smoking history. The pooled HRs of OS (ten trials involving 928 patients) and PFS (five trials involving 465 participants) showed that never smokers in the experimental group had a tendency of reduced risk of death [pooled $\mathrm{HR}=0.81(0.60,1.08), \mathrm{P}=0.15, \mathrm{I}^{2}=63 \%$, Figure S1] or disease progression [pooled HR $=0.92(0.55$,
1.54), $\mathrm{P}=0.23, \mathrm{I}^{2}=82 \%$, Figure $\left.\mathrm{S} 2\right]$ compared with those in the control group.

The interaction analysis showed that the difference of ICI efficacy between current/former and never smokers was significant in terms of OS [interaction HR $=0.77(0.69$, 0.86), $\mathrm{P}<0.00001, \mathrm{I}^{2}=25.4 \%$ ( $\mathrm{P} \_$hetero=0.21), Figure 4]. The significant difference of ICI efficacy between the two types of smoking history remained in terms of PFS [interaction $\mathrm{HR}=0.77(0.71,0.85), \mathrm{P}<0.00001, \mathrm{I}^{2}=89.9 \%\left(\mathrm{P}_{-}\right.$ hetero $<0.0001)$, Figure $\mathrm{S} 3$ ] compared with the controls.

The subgroup analysis was available in terms of line of therapy, study drug and subtype of histology. Because only one type of CTLA-4 inhibitor (ipilimumab) was available, the subgroup analysis by study drugs were based on individual drugs (atezolizumab, avelumab, bevacizumab, durvalumab, ipilimumab, nivolumab, pembrolizumab). The subgroup analysis of ICI efficacy confirmed that current/ former smokers in the experimental group benefited more than those in the control group. For patients without smoking history, subgroup analysis showed that statistical significance was only identified in the subgroup of pembrolizumab [pooled HR $=0.32(0.10,0.98)$ ] in terms of OS (Table S2). At the endpoint of OS, patients with smoking history benefited more from ICI therapy than never smokers based on subgroup analysis of pooled 


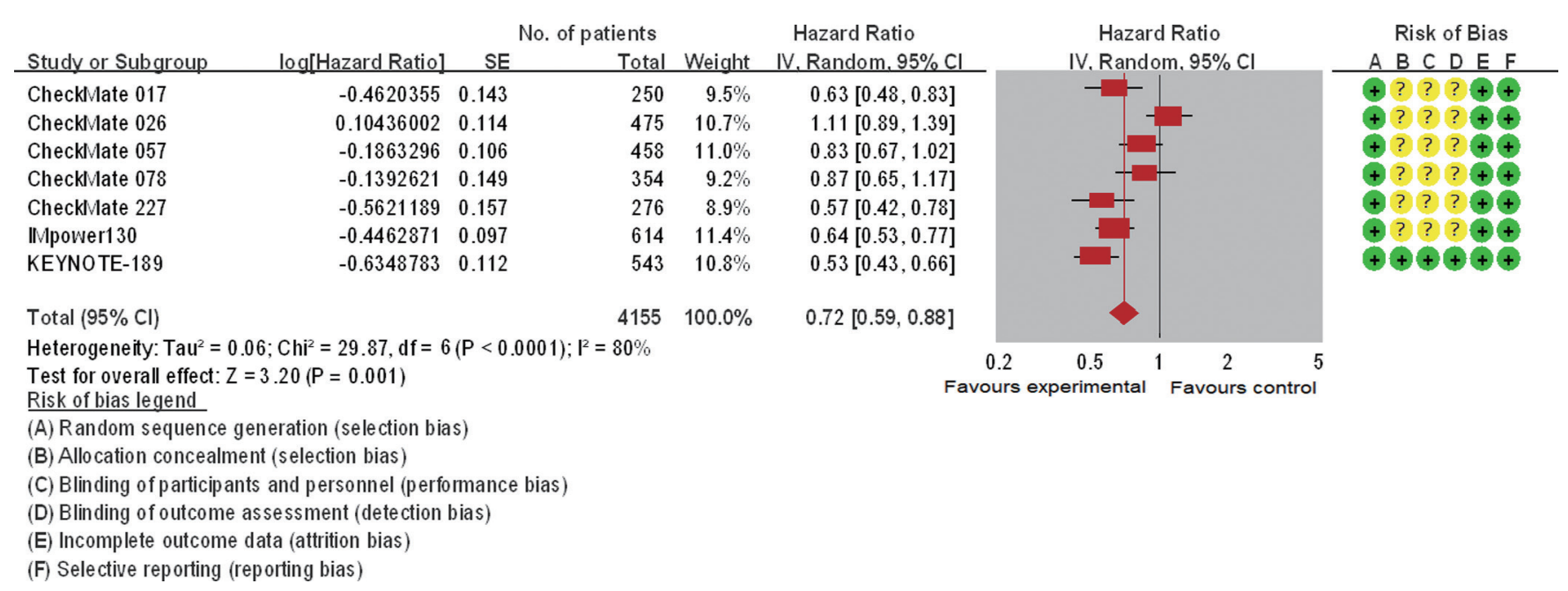

Figure 3 The forest plot displayed progressive-free survival (PFS) of current/former smokers. The risk of bias mainly originated from allocation concealment, blinding of participants and personnel, and blinding of outcome assessment. Severe heterogeneity was discovered across these studies. The pooled hazard ratio based on a random effect model showed a significant improvement of PFS in the experimental group versus control group $(\mathrm{P}<0.0001)$.

interaction HR (Table 2). No significant difference was found between current/former and never smokers at the endpoint of PFS according to subgroup analysis.

The publication bias of each pooled analysis was estimated using a funnel plot (Figures S4-S9). Slight visual publication bias was identified across these studies.

\section{Discussion}

The systematic review and meta-analysis shows that current/ former smokers benefit from the treatment of adding ICIs into chemotherapy compared with the control group. However, there is no significant difference of ICI efficacy between patients with and without smoking history. The current systematic review and meta-analysis only recruited a small number of patients without smoking history $(14.28 \%)$. The number of patients without smoking history included in most of studies is less than 100 (median, 78). Therefore, the pooled HR (95\% CI) at each endpoint (OS or PFS) for never smokers fails to reach a statistical significance. Severe heterogeneity exists across trials in the magnitude of ICI efficacy (both OS and PFS) in patients without smoking history. Several factors may contribute to the heterogeneity, such as the small size of never smokers in each trial, the difference of study drugs, and line of treatment. Thus, the strength of evidence is weak in the population of never smokers. In terms of efficacy of ICIs for never smokers, we cannot make an inference that addition of ICIs is noneffective for patients without smoking history. Because the HRs of OS and PFS for never smokers are evidently less than 1 , we believe that the increase of sample size of never smokers may shrink the corresponding $95 \%$ CI and improve the strength of evidence. In addition, smoking history was not recognized as a stratification factor during the randomized allocation in most of included studies. Hence, future randomized trials focusing on the balance of smoking history across groups are crucial for us to further evaluate the efficacy of ICIs in never smokers.

The interaction analysis shows that the ICI efficacy is similar in both patients with and patients without smoking history. We comprehensively recruited fourteen RCTs, in which two studies only reported the survival data of current/former smokers $(28,30)$. For avoiding ecological bias, these two studies were excluded from interaction analysis between current/former and never smokers. The significant heterogeneity in terms of PFS HR (95\% CI) between current/former and never smokers may originate from the small sample size of non-smokers.

The current stratification of smoking history includes never, former, or current smokers. Some studies calculated the corresponding HR (95\% CI) according to each type of smoking history, and some other trials combined the former and current smokers. In addition, two trials stratified smoking history as heavy and never/former/ 

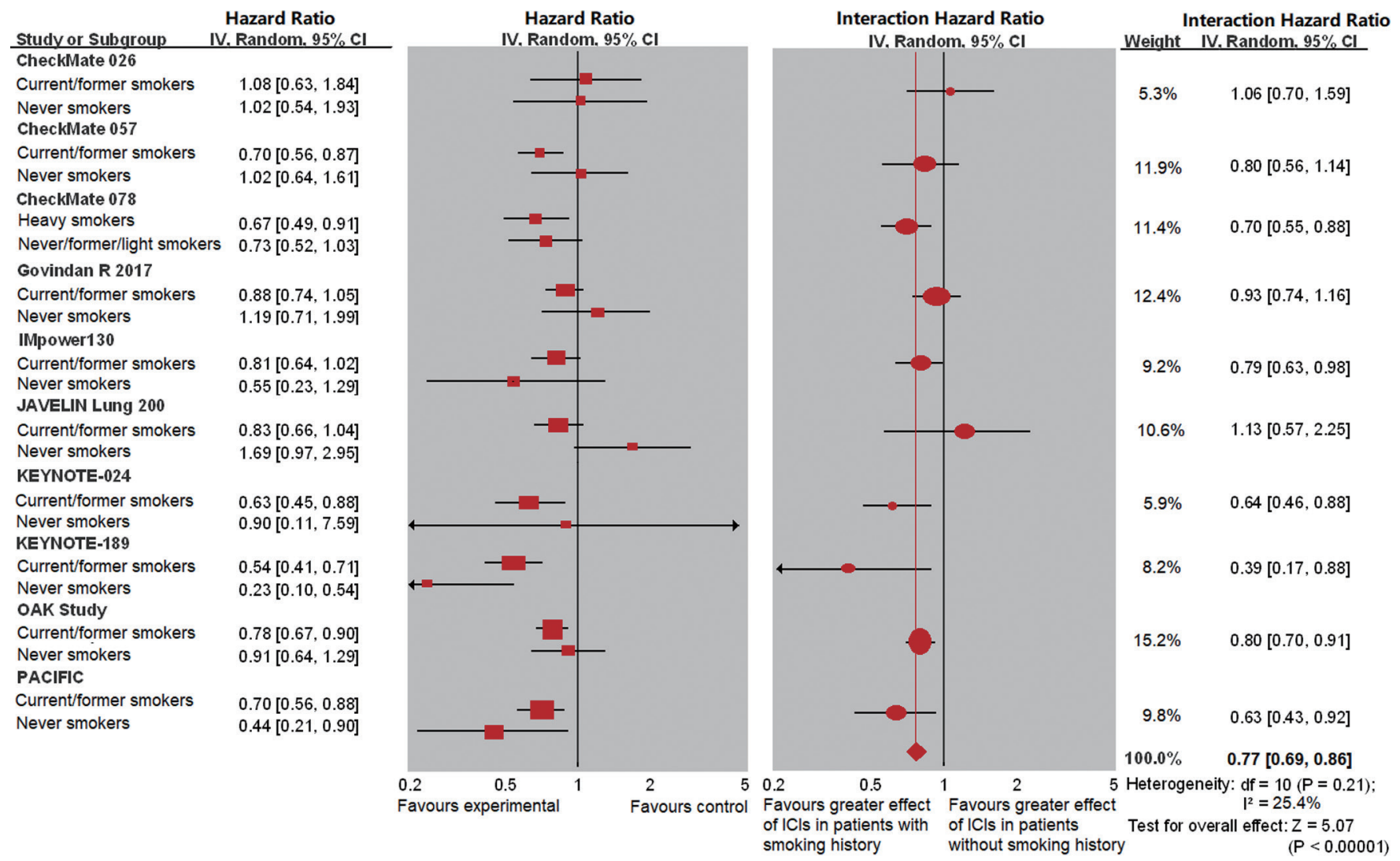

Figure 4 The interaction hazard ratio of overall survival (OS) involved 10 studies by different smoking histories (current/former versus never smokers). The left panel shows the effect of HR (95\% CI) for each subgroup within each trial. The right panel shows the interaction between HR (95\% CI) and smoking history, along with a meta-analysis of the interaction estimates. Mild heterogeneity was discovered across these studies $\left(\mathrm{I}^{2}=25.4 \%, \mathrm{P}=0.21\right)$. There was no significant difference in the efficacy of immune checkpoint inhibitors in terms of OS between never and current/former smokers compared with controls for each smoking status.

light smokers. Therefore, the results of our study in terms of never smokers may be affected by the discrepancy of stratification. However, one advantage of dividing smoking history as heavy and never/former/light smokers is that the severity of smoking is considered. Because the mainstream classification of smoking history ignores the smoking severity, which is commonly determined by the length of smoking years and number of cigarettes smoked every day. We believe that the magnitude of ICI efficacy can be magnified in patients with smoking history and be shrunk in never smokers.

If our results approximate to the truth, what factor(s) can explain the situation? Are there other variables correlated to the efficacy of ICIs (e.g., PD-L1 expression status, gene mutation, and TMB) that are distributed differently between patients with and patients without smoking history? Otherwise, can smoking history be an independent predictor of the efficacy of ICIs in NSCLC patients? Unfortunately, there is insufficient information reported in the included studies for us to further investigate the relationship between smoking history and these variables. As we know, the score of TMB is significantly higher in patients with smoking history than in non-smokers $(34,35)$. Therefore, TMB may be a confounding factor that impacts our understanding about the role of smoking status in immune therapy for NACLC patients.

Recently, three related articles implied that patients with smoking history showed significantly better treatment effect of ICI therapy than non-smokers for NSCLC (36-38). However, the critical shortcoming which resulted in the unreliability of their conclusions is the statistical method. One of them did not report the detailed statistical method (36). The study reported by El-Osta et al. formed the conclusion based on only four studies 
Table 2 Subgroup analysis of pooled interaction hazard ratio comparing current/former with never smokers by therapy line, study drugs and histological subtypes

\begin{tabular}{|c|c|c|c|c|c|c|}
\hline Subgroups & \multicolumn{3}{|c|}{ OS_current/former versus never } & \multicolumn{3}{|c|}{ PFS_current/former versus never } \\
\hline$>1$ st line & 5 & $0.80(0.71,0.91)$ & $\mathrm{I}^{2}=0.0 \% ; \mathrm{P}=0.53$ & 3 & $0.78(0.44,1.38)$ & $\mathrm{I}^{2}=0.0 \% ; \mathrm{P}=0.92$ \\
\hline \multicolumn{7}{|l|}{ Drugs } \\
\hline Beva & 1 & $0.66(0.48,0.90)$ & \multirow{4}{*}{$\begin{array}{c}I^{2}=27.2 \% \\
P=0.22\end{array}$} & 3 & $0.63(0.34,1.16)$ & \multirow{4}{*}{$\begin{array}{c}I^{2}=45.3 \% \\
P=0.14\end{array}$} \\
\hline Nivo & 3 & $0.80(0.64,1.01)$ & & 3 & $1.30(0.65,2.59)$ & \\
\hline Atez & 2 & $0.80(0.71,0.89)$ & & 1 & $0.63(0.35,1.12)$ & \\
\hline Durv & 1 & $0.63(0.43,0.92)$ & & & & \\
\hline \multicolumn{7}{|c|}{ Histological subtypes } \\
\hline NSCLC & 6 & $0.77(0.67,0.87)$ & \multirow{3}{*}{$\begin{array}{c}\mathrm{I}^{2}=36.0 \% \\
P=0.21\end{array}$} & 4 & $1.00(0.66,1.54)$ & \multirow{3}{*}{$\begin{array}{c}\mathrm{I}^{2}=39.9 \% \\
P=0.22\end{array}$} \\
\hline Non-squamous & 4 & $0.72(0.60,0.87)$ & & 4 & $0.60(0.30,1.20)$ & \\
\hline Squamous & 1 & $0.93(0.74,1.16)$ & & & & \\
\hline
\end{tabular}

Atez, atezolizumab; Avel, avelumab; Beva, bevacizumab; Durv, durvalumab; Ipil, ipilimumab; Nivo, nivolumab; OS, overall survival; Pemb, pembrolizumab; PFS, progressive-free survival.

in terms of the ICI efficacy for non-smokers (36). We believe that the conclusions are incorrect. The other two studies investigated the difference of ICI efficacy between smoker and non-smoker by evaluating the inter-group heterogeneity. Mo et al. reported that the inter-group heterogeneity between smoking and non-smoking group was $48 \%$ and the $\mathrm{P}$ value was not displayed (37). Another study reported a significantly high level of inter-group heterogeneity $(76.6 \%, \mathrm{P}=0.04)$ between smoker and nonsmoker group (38). The statistical method used by the above two studies is named the deluded approach which is vulnerable to ecological bias. The biggest superiority of our study versus the above two studies is that we used a more reliable statistical method (the deft approach) to evaluate the difference of ICI efficacy between smoking and nonsmoking group. Therefore, we believe that the present study shown more reliable outcomes.

A strength of the current systematic review and metaanalysis is that all included studies are phase III randomized trials and all but one of those studies have study protocols registered on the clinical trial registration platform. The risk of bias analysis indicates that only several studies were conducted according to the double-blind method. Therefore, the risk of bias mainly generated from procedures related to patient allocation, performance, and outcome assessment. Because we cannot make a judgement of high risk based on insufficient information, the we made a judgement of "unclear risk" for open label trials in terms of selection, performance and detection biases. Nevertheless, we still remind readers that the strength of the results in our systematic review and meta-analysis may be weakened by the above risk of biases.

As is well-known, a large number of study subjects is important for a meta-analysis to draw a substantial conclusion. The total number of participants in our systematic review and meta-analysis is above 6,400, and thus, the finding in terms of NSCLC patients with smoking history is conclusive. However, the small size of never smokers in the present study is a critical limitation against us to draw a decisive conclusion about the efficacy of ICIs 
in NSCLC patients without smoking history. The current meta-analysis is based on published results rather than on the data of individual patients. And we cannot clarify that whether or not variables such as PD-L1 expression status and TMB are distributed unevenly across experimental and control groups. In addition, a slight publication bias exists across the included trials. This situation can be explained by the fact that still many clinical studies do not report the subgroup results based on clinical features, including smoking status. And some studies fail to calculate the relative HR (95\% CI) for never smokers because of the small sample size. The above limitations may also impact the explanation of our results.

\section{Conclusions}

ICIs can improve the OS and PFS of NSCLC patents with smoking history. The current evidences fail to identify a significant higher efficacy of adding ICIs in patients without smoking history, because of the significantly small sample size of never smokers included in each trial. The efficacy of ICIs in patients with smoking history is seemingly superior over that in patients without smoking history. Furthermore, we cannot figure out whether or not other clinicopathological features such as PD-L1 expression status, play a role in the magnitude of ICI efficacy for patients with different smoking histories. We suggest that smoking history cannot be recognized as a predictor of ICI efficacy in patients with advanced NSCLC.

\section{Acknowledgments}

Funding: None.

\section{Footnote}

Reporting Checklist: The authors have completed the PRISMA reporting checklist. Available at http://dx.doi. org/10.21037/jtd-20-1953

Conflicts of Interest: All authors have completed the ICMJE uniform disclosure form (available at http://dx.doi. org/10.21037/jtd-20-1953). The authors have no conflicts of interest to declare.

Ethical Statement: The authors are accountable for all aspects of the work in ensuring that questions related to the accuracy or integrity of any part of the work are appropriately investigated and resolved.

Open Access Statement: This is an Open Access article distributed in accordance with the Creative Commons Attribution-NonCommercial-NoDerivs 4.0 International License (CC BY-NC-ND 4.0), which permits the noncommercial replication and distribution of the article with the strict proviso that no changes or edits are made and the original work is properly cited (including links to both the formal publication through the relevant DOI and the license). See: https://creativecommons.org/licenses/by-nc-nd/4.0/.

\section{References}

1. Global Burden of Disease Cancer Collaboration, Fitzmaurice C, Abate D, et al. Global, Regional, and National Cancer Incidence, Mortality, Years of Life Lost, Years Lived With Disability, and Disability-Adjusted LifeYears for 29 Cancer Groups, 1990 to 2017: A Systematic Analysis for the Global Burden of Disease Study. JAMA Oncol 2019;5:1749-68.

2. Chen $W$, Zheng R, Baade PD, et al. Cancer statistics in China, 2015. CA Cancer J Clin 2016;66:115-32.

3. Eggermont AM, Chiarion-Sileni V, Grob JJ, et al. Prolonged Survival in Stage III Melanoma with Ipilimumab Adjuvant Therapy. $\mathrm{N}$ Engl J Med 2016;375:1845-55.

4. Socinski MA, Jotte RM, Cappuzzo F, et al. Atezolizumab for First-Line Treatment of Metastatic Nonsquamous NSCLC. N Engl J Med 2018;378:2288-301.

5. Vokes EE, Felip E, Horn L, et al. Nivolumab versus docetaxel in previously treated advanced non-small-cell lung cancer (CheckMate 017 and CheckMate 057): 3-year update and outcomes in patients with liver metastases. Ann Oncol 2018;29:959-65.

6. Kazandjian D, Khozin S, Blumenthal G, et al. BenefitRisk Summary of Nivolumab for Patients With Metastatic Squamous Cell Lung Cancer After Platinum-Based Chemotherapy: A Report From the US Food and Drug Administration. JAMA Oncol 2016;2:118-22.

7. Langer CJ, Gadgeel SM, Borghaei H, et al. Carboplatin and pemetrexed with or without pembrolizumab for advanced, non-squamous non-small-cell lung cancer: a randomised, phase 2 cohort of the open-label KEYNOTE-021 study. Lancet Oncol 2016;17:1497-508.

8. Halmos B, Luft A, Majem M, et al. Choice of Taxane and Outcomes in the KEYNOTE-407 Study of Pembrolizumab Plus Chemotherapy for Metastatic 
Squamous NSCLC. J Thorac Oncol 2018;13:S391.

9. Papadimitrakopoulou V, Cobo M, Bordoni R, et al. IMpower132: PFS and Safety Results with 1L Atezolizumab + Carboplatin/Cisplatin + Pemetrexed in Stage IV Non-Squamous NSCLC. J Thorac Oncol 2018;13:S332-3.

10. Thomas M, Kohlhäufl M, Reck M, et al. Long-term outcomes with nivolumab in patients with previously treated advanced Non-Small Cell Lung Cancer (NSCLC). Oncol Res Treat 2017;40:137.

11. Zhou C, Chen G, Huang Y, et al. OA04.03 A Randomized Phase 3 Study of Camrelizumab plus Chemotherapy as 1st Line Therapy for Advanced/Metastatic NonSquamous Non-Small Cell Lung Cancer. J Thorac Oncol 2019;14:S215-6.

12. Garassino M, Rodriguez-Abreu D, Gadgeel S, et al. OA04.06 Evaluation of TMB in KEYNOTE-189: Pembrolizumab Plus Chemotherapy vs Placebo Plus Chemotherapy for Nonsquamous NSCLC. J Thorac Oncol 2019;14:S216-7.

13. Herbst RS, Baas P, Kim DW, et al. Pembrolizumab versus docetaxel for previously treated, PD-L1-positive, advanced non-small-cell lung cancer (KEYNOTE-010): a randomised controlled trial. Lancet 2016;387:1540-50.

14. Paz-Ares L, Luft A, Vicente D, et al. Pembrolizumab plus Chemotherapy for Squamous Non-Small-Cell Lung Cancer. N Engl J Med 2018;379:2040-51.

15. Felip Font E, Gettinger SN, Burgio MA, et al. Three-year follow-up from CheckMate 017/057: Nivolumab versus docetaxel in patients with previously treated advanced nonsmall cell lung cancer (NSCLC). Ann Oncol 2017;28:v462.

16. Gadgeel S, Ciardiello F, Rittmeyer A, et al. OAK, a randomized ph III study of atezolizumab vs docetaxel in patients with advanced NSCLC: Results from subgroup analyses. J Thorac Oncol 2017;12:S9-S10.

17. Conforti F, Pala L, Bagnardi V, et al. Cancer immunotherapy efficacy and patients' sex: a systematic review and meta-analysis. Lancet Oncol 2018;19:737-6.

18. Wu YL, Lu S, Cheng Y, et al. Nivolumab Versus Docetaxel in a Predominantly Chinese Patient Population With Previously Treated Advanced NSCLC: CheckMate 078 Randomized Phase III Clinical Trial. J Thorac Oncol 2019;14:867-75.

19. Reck M, Rodríguez-Abreu D, Robinson AG, et al. Updated Analysis of KEYNOTE-024: Pembrolizumab Versus Platinum-Based Chemotherapy for Advanced NonSmall-Cell Lung Cancer With PD-L1 Tumor Proportion Score of 50\% or Greater. J Clin Oncol 2019;37:537-46.
20. Gandara DR, Paul SM, Kowanetz M, et al. Bloodbased tumor mutational burden as a predictor of clinical benefit in non-small-cell lung cancer patients treated with atezolizumab. Nat Med 2018;24:1441-8.

21. Hellmann MD, Nathanson T, Rizvi H, et al. Genomic Features of Response to Combination Immunotherapy in Patients with Advanced Non-Small-Cell Lung Cancer. Cancer Cell 2018;33:843-852.e4.

22. Higgins JPT, Altman DG, Sterne JAC. editors. Chapter 8: Assessing risk of bias in included studies. In: Higgins JPT, Green S. editors. Cochrane Handbook for Systematic Reviews of Interventions Version 5.1.0 (updated March 2011). The Cochrane Collaboration 2011.

23. Fisher DJ, Carpenter JR, Morris TP, et al. Meta-analytical methods to identify who benefits most from treatments: daft, deluded, or deft approach? BMJ 2017;356:j573.

24. West H, Hussein M, Morabito A, et al. Atezolizumab in combination with carboplatin plus nab-paclitaxel chemotherapy compared with chemotherapy alone as firstline treatment for metastatic non-squamous non-smallcell lung cancer (IMpower130): a multicentre, randomised, open-label, phase 3 trial. Lancet Oncol 2019;20:924-37.

25. Barlesi F, Vansteenkiste J, Spigel D, et al. Avelumab versus docetaxel in patients with platinum-treated advanced non-small-cell lung cancer (JAVELIN Lung 200): an open-label, randomised, phase 3 study. Lancet Oncol 2018;19:1468-79.

26. Gray JE, Villegas A, Daniel D, et al. Three-year overall survival with durvalumab after chemoradiotherapy in Stage III NSCLC-Update from PACIFIC. J Thorac Oncol 2020;15:288-93.

27. Carbone DP, Reck M, Paz-Ares L, et al. First-Line Nivolumab in Stage IV or Recurrent Non-Small-Cell Lung Cancer. N Engl J Med 2017;376:2415-26.

28. Hellmann MD, Ciuleanu TE, Pluzanski A, et al. Nivolumab plus Ipilimumab in Lung Cancer with a High Tumor Mutational Burden. N Engl J Med 2018;378:2093-104.

29. Borghaei H, Paz-Ares L, Horn L, et al. Nivolumab versus Docetaxel in Advanced Nonsquamous Non-Small-Cell Lung Cancer. N Engl J Med 2015;373:1627-39.

30. Brahmer J, Reckamp KL, Baas P, et al. Nivolumab versus Docetaxel in Advanced Squamous-Cell Non-Small-Cell Lung Cancer. N Engl J Med 2015;373:123-35.

31. Gandhi L, Rodriguez-Abreu D, Gadgeel S, et al. Pembrolizumab plus Chemotherapy in Metastatic NonSmall-Cell Lung Cancer. N Engl J Med 2018;378:2078-92.

32. Govindan R, Szczesna A, Ahn MJ, et al. Phase III Trial of Ipilimumab Combined With Paclitaxel and Carboplatin in 


\section{Advanced Squamous Non-Small-Cell Lung Cancer. J Clin} Oncol 2017;35:3449-57.

33. Fehrenbacher L, von Pawel J, Park K, et al. Updated Efficacy Analysis Including Secondary Population Results for OAK: A Randomized Phase III Study of Atezolizumab versus Docetaxel in Patients with Previously Treated Advanced Non-Small Cell Lung Cancer. J Thorac Oncol 2018;13:1156-70.

34. Hu-Lieskovan S, Lisberg A, Zaretsky JM, et al. Tumor characteristics associated with benefit from pembrolizumab in advanced non-small cell lung cancer. Clin Cancer Res 2019;25:5061-8.

35. Rizvi NA, Snyder A, Kvistborg P, et al. Cancer immunology. Mutational landscape determines sensitivity

Cite this article as: Chen DL, Li QY, Tan QY. Smoking history and the efficacy of immune checkpoint inhibitors in patients with advanced non-small cell lung cancer: a systematic review and meta-analysis. J Thorac Dis 2021;13(1):220-231. doi: $10.21037 /$ jtd-20-1953 to PD-1 blockade in non-small cell lung cancer. Science 2015;348:124-8.

36. El-Osta H, Jafri S. Predictors for clinical benefit of immune checkpoint inhibitors in advanced non-smallcell lung cancer: a meta-analysis. Immunotherapy 2019;11:189-99.

37. Mo J, Hu X, Gu L, et al. Smokers or non-smokers: who benefits more from immune checkpoint inhibitors in treatment of malignancies? An up-to-date meta-analysis. World J Surg Oncol 2020;18:15.

38. Lee KWC, Lord SJ, Kasherman L, et al. The impact of smoking on the effectiveness of immune checkpoint inhibitors-a systematic review and meta-analysis. Acta Oncol 2020;59:96-100. 


\section{Appendix 1}

\section{The search strategy of PubMed.}

\#37 Search \#36 AND \#23

\#36 Search \#32 NOT \#35

\#35 Search \#33 NOT \#34

\#34 Search humans[MeSH Terms]

\#33 Search animals[MeSH Terms]

\#32 Search \#24 OR \#25 OR \#26 OR \#27 OR \#28 OR \#29 OR \#30 OR \#31

\#31 Search drug therapy[MeSH Subheading]

\#30 Search trial[Title/Abstract]

\#29 Search groups[Title/Abstract]

\#28 Search randomly[Title/Abstract]

\#27 Search placebo[Title/Abstract]

\#26 Search randomized[Title/Abstract]

\#25 Search controlled clinical trial[Publication Type]

\#24 Search randomized controlled trial[Publication Type]

\#23 Search \#21 AND \#22

\#22 Search \#6 OR \#7 OR \#8 OR \#9 OR \#10 OR \#11 OR \#12 OR \#13 OR \#14 OR \#15 OR \#16 OR \#17 OR \#18 OR \#19 OR \#20

\#21 Search \#1 OR \#2 OR \#3 OR \#4 OR \#5

\#20 Search avelumab[Title/Abstract]

\#19 Search durvalumab[Title/Abstract]

\#18 Search atezolizumab[Title/Abstract]

\#17 Search tremelimumab[Title/Abstract]

\#16 Search ipilimumab[Title/Abstract]

\#15 Search pembrolizumab[Title/Abstract]

\#14 Search nivolumab[Title/Abstract]

\#13 Search B7-H1 Antigen[Title/Abstract]

\#12 Search anti-programmed cell death ligand 1[Title/Abstract]

\#11 Search anti-programmed cell death 1[Title/Abstract]

\#10 Search CTLA-4[Title/Abstract]

\#9 Search PD-L1[Title/Abstract]

\#8 Search PD-1[Title/Abstract]

\#7 Search ICIs[Title/Abstract]

\#6 Search immune checkpoint inhibitor ${ }^{*}[$ Title/Abstract]

\#5 Search NSCLC[Title/Abstract]

\#4 Search non small cell lung carcinoma[Title/Abstract]

\#3 Search non-small cell lung cancer*[Title/Abstract]

\#2 Search non small cell lung cancer*[Title/Abstract]

\#1 Search carcinoma, non small cell lung[MeSH Terms]

\section{The search strategy of Embase.}

\section{\#31. \#22 AND \#30}

\#30. \#23 OR \#24 OR \#25 OR \#26 OR \#27 OR \#28 OR \#29

\#29. 'controlled trial':ti,ab,kw

\#28. 'groups':ti,ab,kw

\#27. 'control':ti,ab,kw

\#26. 'random**':ti,ab,kw

\#25. 'randomly':ti,ab,kw

\#24. 'randomized':ti,ab, kw

\#23. 'randomized controlled trial':ti,ab,kw

\#22. \#4 AND \#21 


\section{OR \#20}

\#20. 'nivolumab':ti,ab,kw

\#19. 'pembrolizumab':ti,ab,kw

\#18. 'ipilimumab':ti,ab,kw

\#17. 'tremelimumab':ti,ab,kw

\#16. 'ticilimumab':ti,ab,kw

\#15. 'atezolizumab':ti,ab,kw

\#14. 'durvalumab':ti,ab,kw

\#13. 'avelumab':ti,ab,kw

\#12. 'anti-cytotoxic t lymphocyte associated antigen 4 ':ti,ab,kw

\#11. 'ctla-4':ti,ab,kw\#10. 'anti-programmed cell death ligand 1':ti,ab,kw

\#9. 'anti-programmed cell death 1 ':ti,ab,kw

\#8. 'pd-11':ti,ab,kw

\#7. 'pd-1':ti,ab,kw

\#6. 'immune checkpoint inhibitor*':ti,ab,kw

\#5. 'ici':ti,ab,kw

\#4. \#1 OR \#2 OR \#3

\#3. 'non small cell lung carcinoma':ti,ab,kw

\#2. 'nsclc':ti,ab,kw

\#1. 'non small cell lung cancer':ti,ab,kw

\section{The search strategy of Cochrane library.}

\#1 MeSH descriptor: [Carcinoma, Non-Small-Cell Lung] explode all trees

\#2 (non small cell lung cancer):ti,ab,kw

\#3 ("non small cell lung carcinoma"):ti,ab,kw

\#4 (nonsmall cell lung cnacer):ti,ab,kw

\#5 (NSCLC):ti,ab,kw

\#6 \{OR \#1-\#5\}

\#7 (immune checkpoint inhibitor*):ti,ab,kw

\#8 (ICI):ti,ab,kw

\#9 (PD-1):ti,ab,kw

\#10 (PD-L1):ti,ab,kw

\#11 (anti-programmed cell death 1):ti,ab,kw

\#12 (anti-programmed cell death ligand 1):ti,ab,kw

\#13 (CTLA-4):ti,ab,kw

\#14 (cytotoxic T lymphocyte antigen 4):ti,ab,kw

\#15 \{OR \#7-\#14\}

\#16 (avelumab):ti,ab,kw

\#17 (durvalumab):ti,ab,kw

\#18 (atezolizumab):ti,ab,kw

\#19 (tremelimumab):ti,ab,kw

\#20 (ipilimumab):ti,ab,kw

\#21 (pembrolizumab):ti,ab,kw

\#22 (nivolumab):ti,ab,kw

\#23 \{OR \#15-\#22\}

\#24 \{AND \#6, \#23\}

\#25 (random*):ti,ab,kw

\#26 (control):ti,ab,kw

\#27 (trial):ti,ab,kw

\#28 (placebo):ti,ab,kw

\#29 (groups):ti,ab,kw

\#30 \{OR \#25-\#29\}

\#31 $\{$ AND \#24, \#30\} 
Table S1 The risk of bias of included studies according to the 'risk of bias' assessment tool of Cochrane Handbook for Systematic Review of Interventions

\begin{tabular}{|c|c|c|c|c|c|c|}
\hline Study ID & Random sequence generation & Allocation concealment & Blinding of participants and personnel & Blinding of outcome assessment & Incomplete outcome data addressed & Selective reporting \\
\hline CheckMate 017 & $\begin{array}{l}\text { Low risk. Quote: "We randomly } \\
\text { assigned... in a 1:1 ratio..." }\end{array}$ & $\begin{array}{l}\text { Unclear risk. Quote: "The trial was open } \\
\text { label...". But insufficient information to } \\
\text { permit judge of high or low risk. }\end{array}$ & $\begin{array}{l}\text { Unclear risk. Quote: "The trial was open } \\
\text { label...". But insufficient information to } \\
\text { permit judge of high or low risk. }\end{array}$ & $\begin{array}{l}\text { Unclear risk. Quote: "The trial was open } \\
\text { label...". But insufficient information to } \\
\text { permit judge of high or low risk. }\end{array}$ & $\begin{array}{l}\text { Low risk. Only } 12(4 \%) \text { didn't receive } \\
\text { treatment with a study drug after } \\
\text { randomization. All participants finished } \\
\text { follow-up. }\end{array}$ & $\begin{array}{l}\text { Low risk. The conformity between } \\
\text { protocol and reported outcomes. }\end{array}$ \\
\hline CheckMate 057 & $\begin{array}{l}\text { Low risk. Quote: "Patients were } \\
\text { randomized to... in a 1:1 ratio..." }\end{array}$ & $\begin{array}{l}\text { Unclear risk. Quote: “The trial was open } \\
\text { label...". But insufficient information to } \\
\text { permit judge of high or low risk. }\end{array}$ & $\begin{array}{l}\text { Unclear risk. Quote: "The trial was open } \\
\text { label...". But insufficient information to } \\
\text { permit judge of high or low risk. }\end{array}$ & $\begin{array}{l}\text { Unclear risk. Quote: “The trial was open } \\
\text { label...". But insufficient information to } \\
\text { permit judge of high or low risk. }\end{array}$ & Low risk. No missing outcome data. & $\begin{array}{l}\text { Low risk. The conformity between } \\
\text { protocol and reported outcomes. }\end{array}$ \\
\hline CheckMate 078 & $\begin{array}{l}\text { Low risk. Quote: "Patients were } \\
\text { randomly assigned 2:1 to..." }\end{array}$ & $\begin{array}{l}\text { Unclear risk. Quote: "The trial was open } \\
\text { label...". But insufficient information to } \\
\text { permit judge of high or low risk. }\end{array}$ & $\begin{array}{l}\text { Unclear risk. Quote: "The trial was open } \\
\text { label...". But insufficient information to } \\
\text { permit judge of high or low risk. }\end{array}$ & $\begin{array}{l}\text { Unclear risk. Quote: "The trial was open } \\
\text { label...". But insufficient information to } \\
\text { permit judge of high or low risk. }\end{array}$ & $\begin{array}{l}\text { Low risk. Only } 1 \text { patients in the } \\
\text { experimental group and } 10 \text { patients } \\
\text { in the control group didn't receive } \\
\text { treatment after randomization. All } \\
\text { participants finished follow-up. }\end{array}$ & $\begin{array}{l}\text { Low risk. The conformity between } \\
\text { protocol and reported outcomes. }\end{array}$ \\
\hline CheckMate 227 & $\begin{array}{l}\text { Low risk. Quote: "randomly assigned (in } \\
\text { a 1:1:1 ratio)..." }\end{array}$ & $\begin{array}{l}\text { Unclear risk. Quote: "The trial was open } \\
\text { label...". But insufficient information to } \\
\text { permit judge of high or low risk. }\end{array}$ & $\begin{array}{l}\text { Unclear risk. Quote: "The trial was open } \\
\text { label...". But insufficient information to } \\
\text { permit judge of high or low risk. }\end{array}$ & $\begin{array}{l}\text { Unclear risk. Quote: "The trial was open } \\
\text { label...". But insufficient information to } \\
\text { permit judge of high or low risk. }\end{array}$ & Low risk. No missing outcome data. & $\begin{array}{l}\text { Low risk. The conformity between } \\
\text { protocol and reported outcomes. }\end{array}$ \\
\hline Govindan R 2017 & $\begin{array}{l}\text { Low risk. Quote: "Patients...were } \\
\text { randomly assigned (1:1) to..." }\end{array}$ & $\begin{array}{l}\text { Low risk. Quote: "In this double-blind } \\
\text { trial..." }\end{array}$ & $\begin{array}{l}\text { Low risk. Quote: "In this double-blind } \\
\text { trial..." }\end{array}$ & $\begin{array}{l}\text { Low risk. Quote: "In this double-blind } \\
\text { trial..." }\end{array}$ & Low risk. No missing outcome data. & $\begin{array}{l}\text { Low risk. The conformity between } \\
\text { protocol and reported outcomes. }\end{array}$ \\
\hline IMpower130 & $\begin{array}{l}\text { Low risk. Quote: "Patients were } \\
\text { randomly assigned with permuted block } \\
\text { randomisation (block size of six)...." }\end{array}$ & $\begin{array}{l}\text { Unclear risk. Quote: "The trial was open } \\
\text { label...". But insufficient information to } \\
\text { permit judge of high or low risk. }\end{array}$ & $\begin{array}{l}\text { Unclear risk. Quote: "The trial was open } \\
\text { label...". But insufficient information to } \\
\text { permit judge of high or low risk. }\end{array}$ & $\begin{array}{l}\text { Unclear risk. Quote: "The trial was open } \\
\text { label...". But insufficient information to } \\
\text { permit judge of high or low risk. }\end{array}$ & $\begin{array}{l}\text { Low risk. One patient died before } \\
\text { randomization, this patient was } \\
\text { excluded from the intention-to-treat } \\
\text { population. }\end{array}$ & $\begin{array}{l}\text { Low risk. The conformity between } \\
\text { protocol and reported outcomes. }\end{array}$ \\
\hline JAVELIN Lung 200 & $\begin{array}{l}\text { Low risk. Quote: "Patients were } \\
\text {...were Randomly assigned (1:1) via an } \\
\text { interactive voice-response system" }\end{array}$ & $\begin{array}{l}\text { Unclear risk. Quote: "The trial was open } \\
\text { label...". But insufficient information to } \\
\text { permit judge of high or low risk. }\end{array}$ & $\begin{array}{l}\text { Unclear risk. Quote: "...neither } \\
\text { investigators nor patients were masked } \\
\text { to assigned study treatments." But } \\
\text { insufficient information to permit judge } \\
\text { of high or low risk. }\end{array}$ & $\begin{array}{l}\text { Unclear risk. Quote: “...neither } \\
\text { investigators nor patients were masked } \\
\text { to assigned study treatments." But } \\
\text { insufficient information to permit judge } \\
\text { of high or low risk. }\end{array}$ & Low risk. No missing outcome data. & $\begin{array}{l}\text { Low risk. The conformity between } \\
\text { protocol and reported outcomes. }\end{array}$ \\
\hline KEYNOTE-024 & $\begin{array}{l}\text { Low risk. Quote: "Eligible patients were } \\
\text { randomly assigned (1:1)..." }\end{array}$ & $\begin{array}{l}\text { Unclear risk. Quote: "The trial was open } \\
\text { label...". But insufficient information to } \\
\text { permit judge of high or low risk. }\end{array}$ & $\begin{array}{l}\text { Unclear risk. Quote: "The trial was open } \\
\text { label...". But insufficient information to } \\
\text { permit judge of high or low risk. }\end{array}$ & $\begin{array}{l}\text { Unclear risk. Quote: “The trial was open } \\
\text { label...". But insufficient information to } \\
\text { permit judge of high or low risk. }\end{array}$ & Low risk. No missing outcome data. & $\begin{array}{l}\text { Low risk. The conformity between } \\
\text { protocol and reported outcomes. }\end{array}$ \\
\hline KEYNOTE-189 & $\begin{array}{l}\text { Low risk. Quote: "we randomly assigned } \\
\text { (in a 2:1 ratio)..." }\end{array}$ & $\begin{array}{l}\text { Low risk. Quote: "In this double-blind } \\
\text { trial..." }\end{array}$ & $\begin{array}{l}\text { Low risk. Quote: "In this double-blind } \\
\text { trial..." }\end{array}$ & $\begin{array}{l}\text { Low risk. Quote: "In this double-blind } \\
\text { trial..." }\end{array}$ & $\begin{array}{l}\text { Low risk. Only } 5 \text { patients in the } \\
\text { experimental group and } 4 \text { patients in the } \\
\text { control group didn't receive treatment } \\
\text { with a study drug after randomization. } \\
\text { All participants finished follow-up. }\end{array}$ & $\begin{array}{l}\text { Low risk. The conformity between } \\
\text { protocol and reported outcomes. }\end{array}$ \\
\hline OAK Study & $\begin{array}{l}\text { Low risk. Quote: "Permuted block- } \\
\text { randomisation (block size of eight) via } \\
\text { an interactive voice or web response } \\
\text { system (bracket) was used to assign } \\
\text { patients in a 1:1 ratio to..." }\end{array}$ & $\begin{array}{l}\text { Unclear risk. Quote: "The trial was open } \\
\text { label...". But insufficient information to } \\
\text { permit judge of high or low risk. }\end{array}$ & $\begin{array}{l}\text { Unclear risk. Quote: "The trial was open } \\
\text { label...". But insufficient information to } \\
\text { permit judge of high or low risk. }\end{array}$ & $\begin{array}{l}\text { Unclear risk. Quote: "The trial was open } \\
\text { label...". But insufficient information to } \\
\text { permit judge of high or low risk. }\end{array}$ & Low risk. No missing outcome data. & $\begin{array}{l}\text { Low risk. The conformity between } \\
\text { protocol and reported outcomes. }\end{array}$ \\
\hline PACIFIC & $\begin{array}{l}\text { Low risk. Quote: "We randomly assigned } \\
\text { patients, in a 2:1 ratio..." }\end{array}$ & $\begin{array}{l}\text { Low risk. Quote: "In this double-blind } \\
\text { trial..." }\end{array}$ & $\begin{array}{l}\text { Low risk. Quote: "In this double-blind } \\
\text { trial..." }\end{array}$ & $\begin{array}{l}\text { Low risk. Quote: "In this double-blind } \\
\text { trial..." }\end{array}$ & Low risk. No missing outcome data. & $\begin{array}{l}\text { Low risk. The conformity between } \\
\text { protocol and reported outcomes. }\end{array}$ \\
\hline
\end{tabular}


Table S2 Subgroup analysis of smoking status specific pooled hazard ratio (OS and PFS)

\begin{tabular}{|c|c|c|c|c|c|c|c|c|c|c|c|c|}
\hline \multirow[b]{2}{*}{ Subgroups } & \multicolumn{3}{|c|}{ OS_Never smokers } & \multicolumn{3}{|c|}{ OS_Current/former smokers } & \multicolumn{3}{|c|}{ PFS_Never smokers } & \multicolumn{3}{|c|}{ PFS_Current/former smokers } \\
\hline & $\begin{array}{l}\text { No. of } \\
\text { trials }\end{array}$ & Pooled HR & $\begin{array}{c}\text { Inter-group } \\
\text { heterogeneity }\end{array}$ & $\begin{array}{l}\text { No. of } \\
\text { trials }\end{array}$ & Pooled HR & $\begin{array}{c}\text { Inter-group } \\
\text { heterogeneity }\end{array}$ & $\begin{array}{l}\text { No. of } \\
\text { trials }\end{array}$ & Pooled HR & $\begin{array}{c}\text { Inter-group } \\
\text { heterogeneity }\end{array}$ & $\begin{array}{l}\text { No. of } \\
\text { trials }\end{array}$ & Pooled HR & $\begin{array}{c}\text { Inter-group } \\
\text { heterogeneity }\end{array}$ \\
\hline \multicolumn{13}{|l|}{ Lines } \\
\hline$>1$ st line & 6 & $0.75(0.50,1.12)$ & \multirow{2}{*}{$\begin{array}{c}\mathrm{I}^{2}=0.0 \% ; \\
P=0.32\end{array}$} & 7 & $0.82(0.70,0.96)$ & \multirow{2}{*}{$\begin{array}{c}I^{2}=59.1 \% \\
P=0.12\end{array}$} & 3 & $0.78(0.44,1.38)$ & \multirow{2}{*}{$\begin{array}{c}\mathrm{I}^{2}=0.0 \% \\
\mathrm{P}=0.53\end{array}$} & 4 & $0.70(0.55,0.89)$ & \multirow{2}{*}{$\begin{array}{c}\mathrm{I}^{2}=0.0 \% \\
\mathrm{P}=0.79\end{array}$} \\
\hline 1st line & 5 & $0.98(0.69,1.40)$ & & 5 & $0.71(0.63,0.79)$ & & 5 & $1.25(0.32,4.81)$ & & 6 & $0.74(0.50,1.11)$ & \\
\hline \multicolumn{13}{|l|}{ Drugs } \\
\hline Nivolumab & 3 & $0.83(0.61,1.12)$ & \multirow{6}{*}{$\begin{array}{c}I^{2}=66.3 \% \\
P=0.02\end{array}$} & 4 & $0.70(0.60,0.81)$ & \multirow{6}{*}{$\begin{array}{c}\mathrm{I}^{2}=58.5 \% \\
\mathrm{P}=0.03\end{array}$} & 3 & $0.98(0.79,1.22)$ & \multirow{6}{*}{$\begin{array}{c}\mathrm{I}^{2}=72.5 \% \\
P=0.03\end{array}$} & 5 & $0.82(0.73,0.92)$ & \multirow{6}{*}{$\begin{array}{c}I^{2}=85.6 \% \\
P=0.001\end{array}$} \\
\hline Atezolizumab & 2 & $0.83(0.56,1.22)$ & & 2 & $0.79(0.70,0.89)$ & & 1 & $0.63(0.35,1.12)$ & & 1 & $0.64(0.53,0.77)$ & \\
\hline Pembrolizumab & 2 & $0.32(0.10,0.98)$ & & 2 & $0.57(0.47,0.71)$ & & 1 & $0.43(0.23,0.81)$ & & 1 & $0.53(0.43,0.66)$ & \\
\hline Avelumab & 1 & $1.69(0.97,2.95)$ & & 1 & $0.83(0.66,1.04)$ & & & & & & & \\
\hline Ipilimumab & 1 & $1.19(0.71,1.99)$ & & 1 & $0.88(0.74,1.05)$ & & & & & & & \\
\hline Durvalumab & 1 & $0.44(0.21,0.90)$ & & 1 & $0.70(0.56,0.88)$ & & & & & & & \\
\hline \multicolumn{13}{|c|}{ Histological subtypes } \\
\hline NSCLC & 6 & $0.81(0.60,1.08)$ & \multirow{3}{*}{$\begin{array}{c}I^{2}=20.3 \% \\
P=0.29\end{array}$} & 6 & $0.73(0.66,0.81)$ & \multirow{3}{*}{$\begin{array}{c}\mathrm{I}^{2}=9.2 \% \\
\mathrm{P}=0.33\end{array}$} & 4 & $1.30(0.38,4.38)$ & \multirow{3}{*}{$\begin{array}{c}\mathrm{I}^{2}=0.0 \% \\
\mathrm{P}=0.44\end{array}$} & 5 & $0.83(0.57,1.21)$ & \multirow[t]{3}{*}{$\mathrm{I}^{2}=0 \% ; P=0.13$} \\
\hline Non-squamous & 4 & $0.53(0.22,1.30)$ & & 4 & $0.65(0.53,0.79)$ & & 4 & $0.74(0.36,1.53)$ & & 4 & $0.66(0.51,0.84)$ & \\
\hline Squamous & 1 & $1.19(0.71,1.99)$ & & 2 & $0.73(0.50,1.09)$ & & & & & 1 & $0.63(0.48,0.83)$ & \\
\hline
\end{tabular}

OS, overall survival; PFS, progressive-free survival.

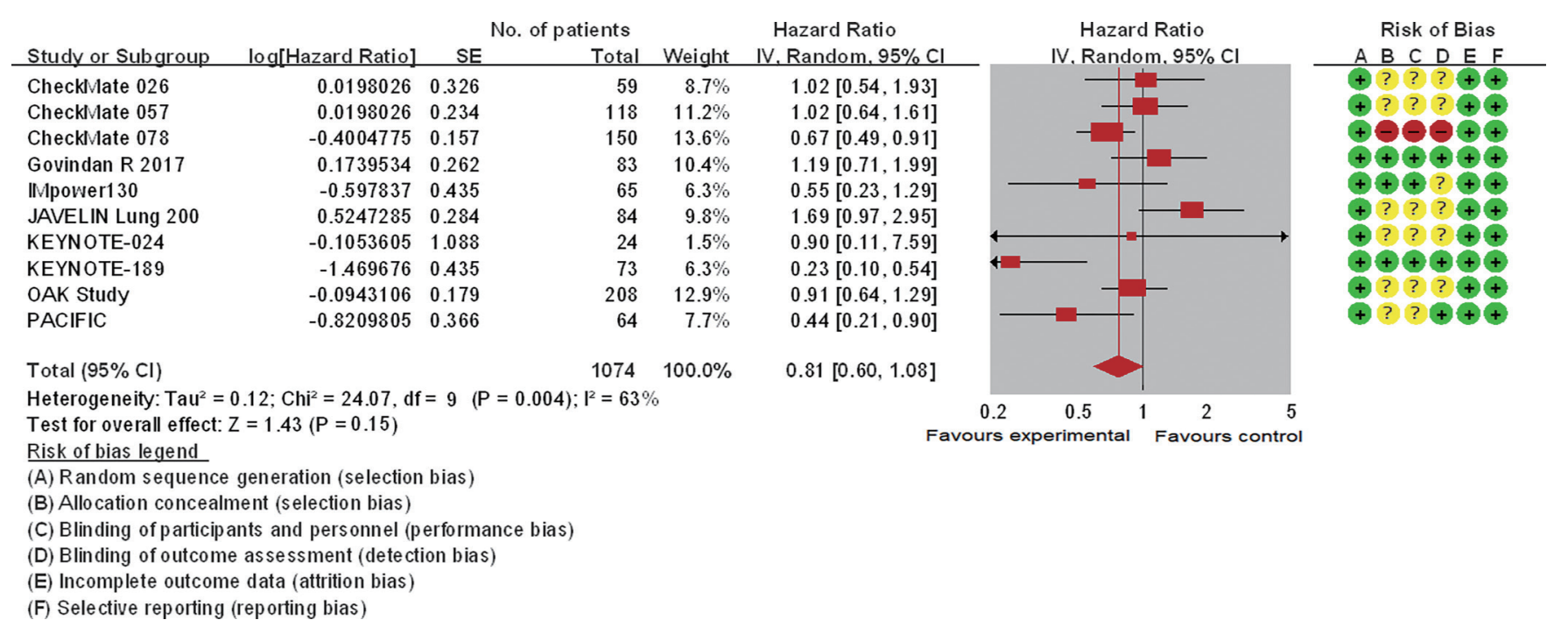

Figure S1 The forest plot involved 11 eligible studies and 1,074 participants in terms of overall survival (OS) of non-smokers. The risk of bias mainly originated from allocation concealment, blinding of participants and personnel and blinding of outcome assessment. And severe heterogeneity was identified across these studies. The pooled hazard ratio based on random effect model showed a tendency of improvement of $\mathrm{OS}$ in the experimental group versus control group without statistical significance $(\mathrm{P}=0.15)$. 


\begin{tabular}{lrrrrr} 
& \multicolumn{3}{c}{ No. of patients } & Hazard Ratio \\
Study or Subgroup & log[Hazard Ratio] & SE & Total & Weight & IV. Random. $95 \% \mathrm{Cl}$
\end{tabular}

Figure S2 The forest plot involved 7 eligible studies (8 trials) and 946 participants in terms of progressive-free survival (PFS) of nonsmokers. The risk of bias mainly originated from allocation concealment, blinding of participants and personnel and blinding of outcome assessment. And extreme heterogeneity was identified across these studies. The pooled hazard ratio based on random effect model showed a tendency of improvement of PFS in the experimental group versus control group without statistical significance $(\mathrm{P}=0.23)$.

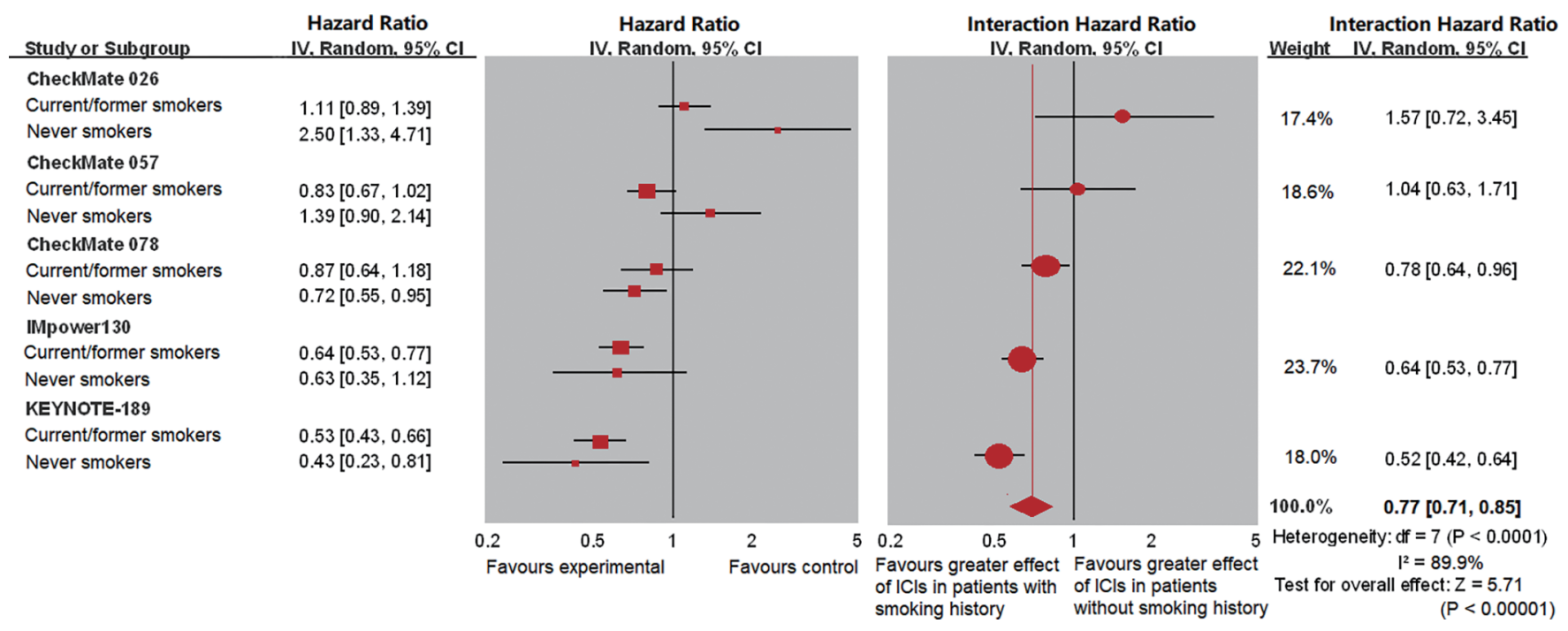

Figure S3 The interaction hazard ratio of progressive-free survival (PFS) involved 8 studies by smoking history (current/former versus never smokers). The left panel shows the effect of HR (95\% CI) for each subgroup within each trial. The right panel shows the interaction between HR (95\% CI) and smoking history, along with a meta-analysis of the interaction estimates. And severe heterogeneity was discovered across these studies $\left(\mathrm{I}^{2}=89.9 \%, \mathrm{P}<0.00001\right)$. It showed that there was a significant difference in the efficacy of immune checkpoint inhibitors in terms of PFS between never and current/former smokers, when compared with controls for each smoking status. 


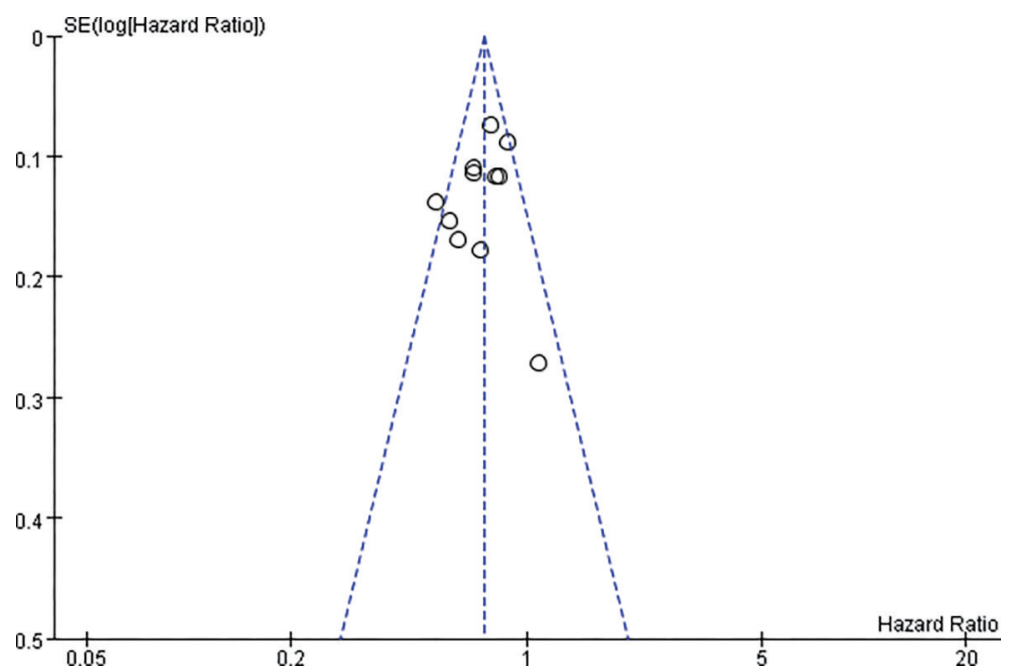

Figure S4 The funnel plot was generated across studies reporting overall survival data of current/former smokers. There has no obvious publication bias across included studies according to the plot.

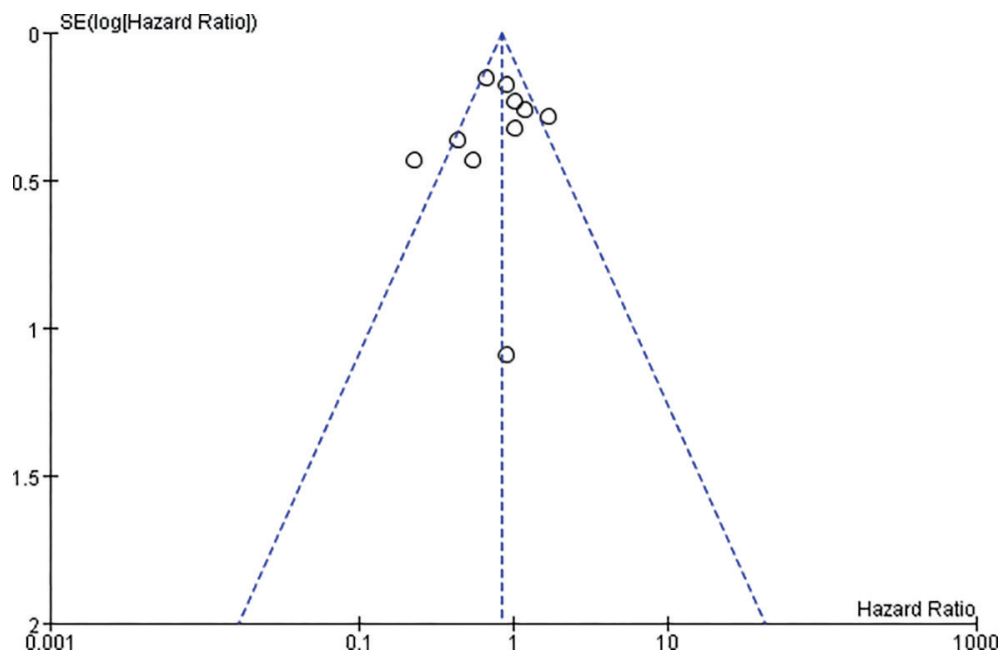

Figure S5 The funnel plot was generated across studies reporting overall survival data of non-smokers. There has a slight publication bias across included studies according to the plot.

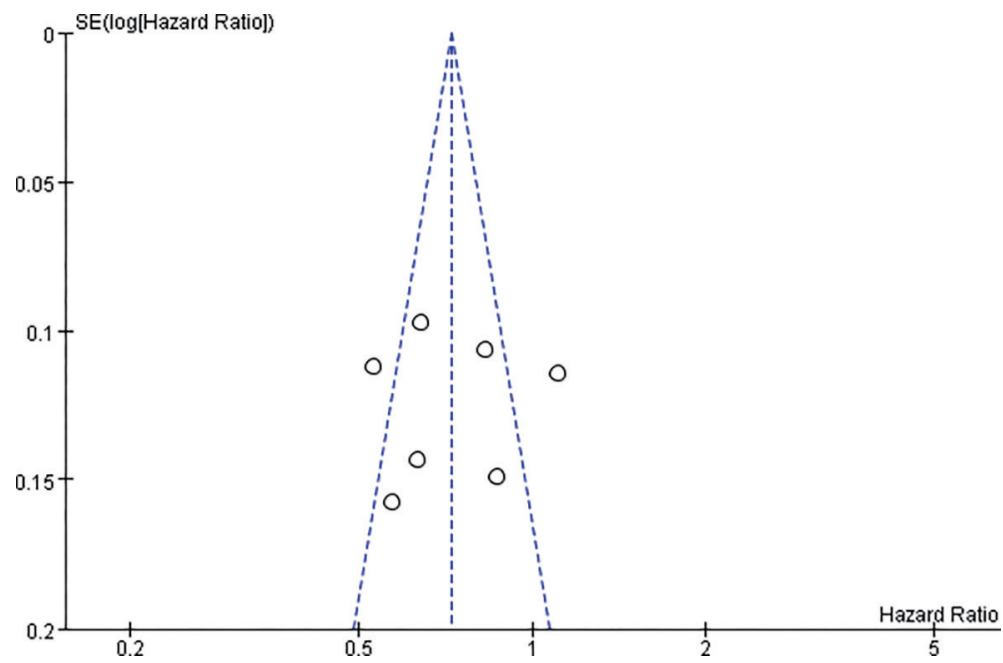

Figure S6 The funnel plot was generated across studies reporting progressive-free survival data of current/former smokers. There has a slight publication bias across included studies according to the plot. 


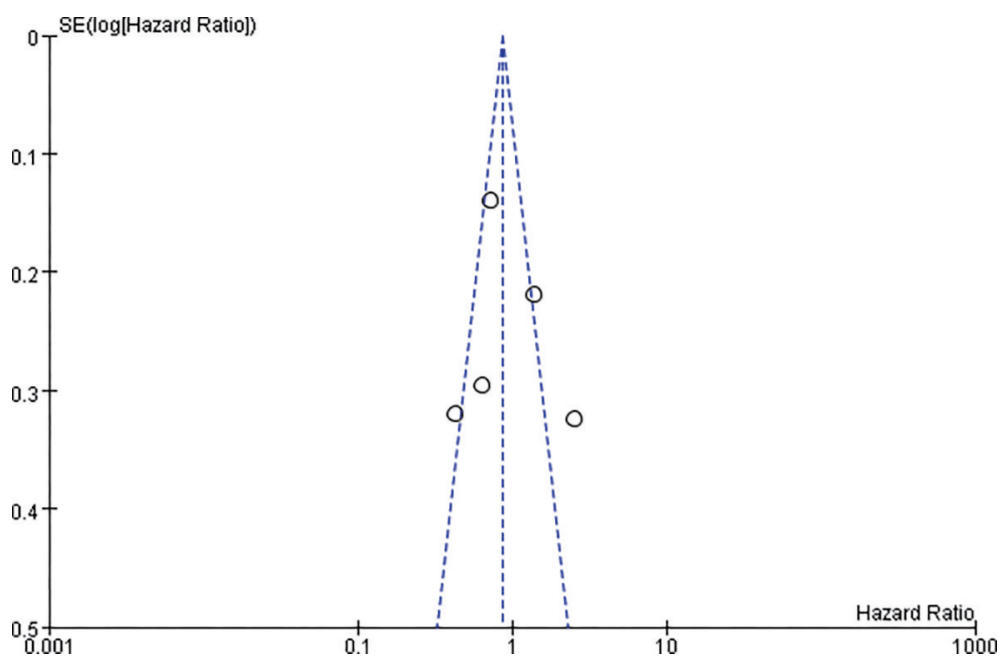

Figure S7 The funnel plot was generated across studies reporting progressive-free survival data of non-smokers. There has a slight publication bias across included studies according to the plot.

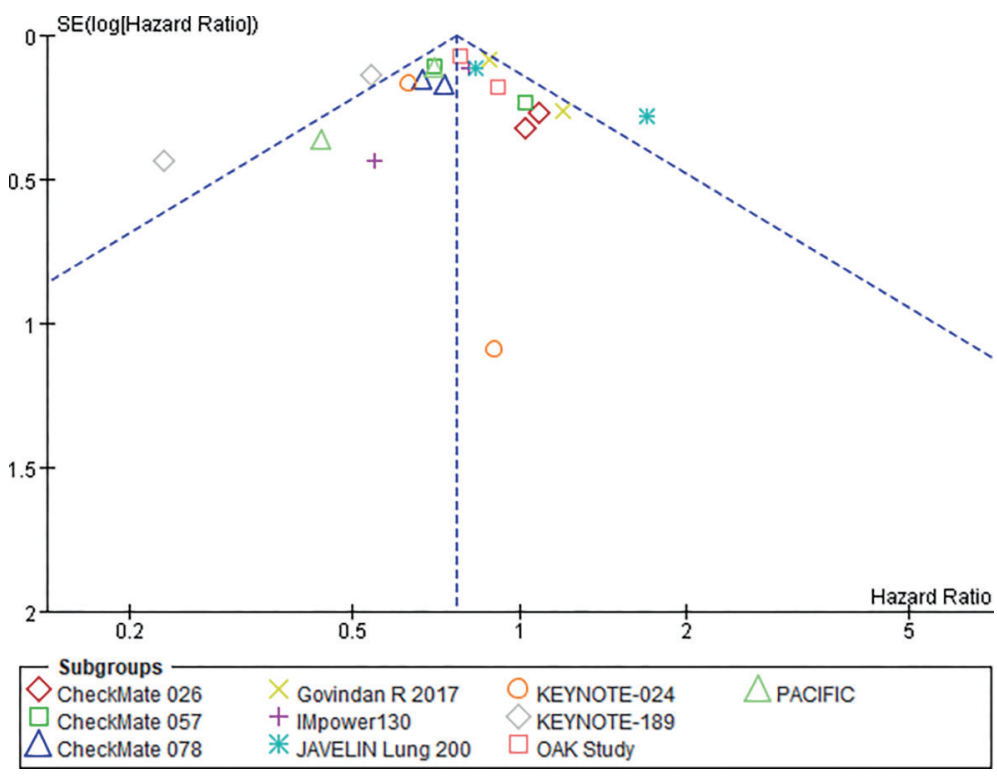

Figure S8 The funnel plot was generated across studies reporting overall survival data comparing current/former with never smokers. There has a slight publication bias across included studies according to the plot.

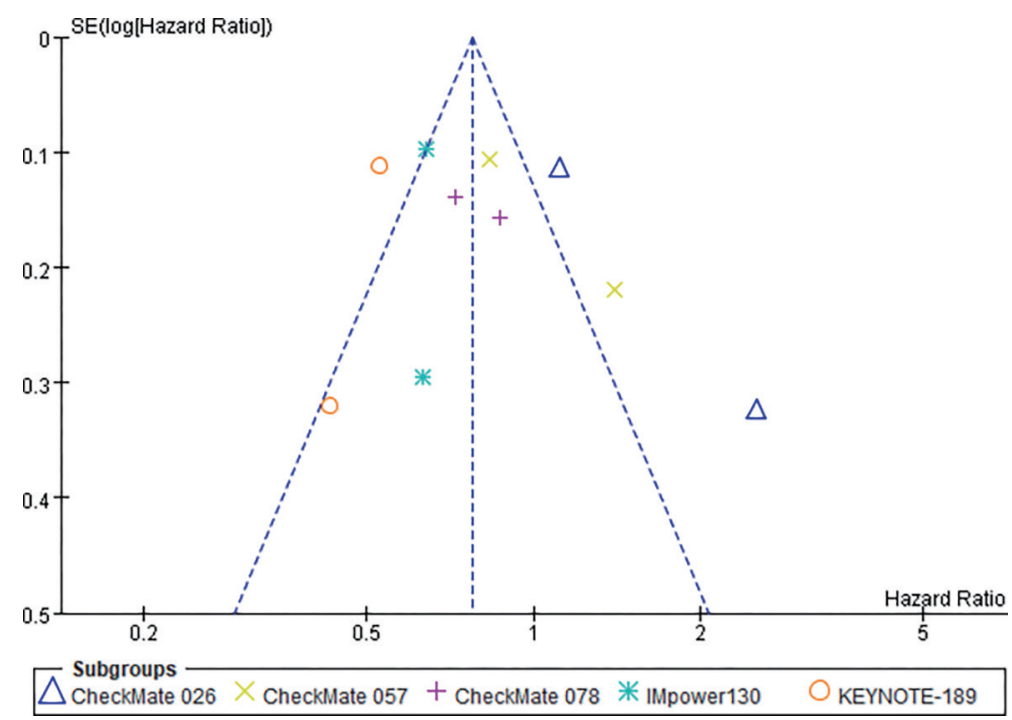

Figure S9 The funnel plot was generated across studies reporting progressive-free survival data comparing current/former with never smokers. There has a median publication bias across included studies according to the plot. 